\title{
COVID-19 and the Response of Transplant Centers: the Global Response with an Emphasis on the Kidney Recipient
}

\author{
Yorg Azzi ${ }^{1,2} \cdot$ Abigail Brooks $^{1,2} \cdot$ Hillary Yaffe ${ }^{1,2} \cdot$ Stuart Greenstein ${ }^{1,2}$ (D) \\ Accepted: 22 May 2021 / Published online: 29 June 2021 \\ (C) The Author(s), under exclusive licence to Springer Nature Switzerland AG 2021
}

\begin{abstract}
Purpose of the Review In response to the COVID-19 pandemic, vulnerable populations, such as transplant patients, were at greater risk than the regular population. In order to protect these populations, transplant centers enacted new guidelines. We approach this review by looking at how different transplant regions responded to COVID-19 and analyze the unifying themes that have proven invaluable in the subsequent waves.

Recent Findings We noticed that most elective surgeries including living donor transplant operations were suspended in most countries. The response to deceased donor transplants varied between countries: in some deceased donor transplants continued with modified donor and recipient criteria, while in other countries this surgery was suspended. There was a general trend of decreasing or holding antimetabolites, treating the virus with hydroxychloroquine and/or azithromycin, and converting outpatient clinics to virtual clinics.

Summary We learned how to carefully select donors and recipients, tailor immunosuppressant regiments, and implement telemedicine. The kidney recipient population can be effectively managed in times of crisis with appropriate accommodations and measures. This review can be a model for the transplant community for future pandemics.
\end{abstract}

Keywords Transplant response to COVID-19 · Kidney recipients and COVID-19 · Review of transplant response to COVID-19 . COVID-19 in the transplant community

\section{Introduction}

In the winter of 2020, the first wave of SARS-CoV-2, the virus that causes coronavirus-19 (COVID-19) infection emerged from Wuhan, China. This virus spread rapidly through the world in an unprecedented way that has yet to abate. As the COVID-19 global pandemic erupted, the care of vulnerable populations was one of the primary challenges. Among them are the solid organ transplant patients, on account of their immunosuppressed status. In particular, the T cell response is significantly suppressed in this population $[1 \bullet \bullet, 2 \bullet, 3,4]$. At the outset of the pandemic, when the natural

This article is part of the Topical Collection on Kidney Transplantation

Stuart Greenstein

SGREENST@montefiore.org

1 Albert Einstein College of Medicine, Bronx, NY, USA

2 Montefiore-Einstein Center for Transplantation, Montefiore Medical Center, 111 East 210th Street, Bronx, NY 10467-2401, USA history of COVID-19 infection could only be conjectured, there was bona fide concern that immunosuppressed patients would be at increased risk for infection with SARS-CoV-2 and would experience unacceptably high mortality rates [3-7]. Faced with this hypothesis, solid organ transplant programs needed to make important decisions about very practical matters $[7,8]$. Is the inpatient transplant unit sufficiently physically distant from the COVID-19 unit? Should postoperative patients be seen in the outpatient clinic? How should the medical personnel be protected? Should induction immunosuppression not include lymphocyte depleting agents? Should only some transplants be performed? Should any transplants be performed?

Around the world, transplant centers made individualized decisions about the conduct of their programs, though several themes were mostly consistent: pre-operative testing of recipients and donors for COVID-19 infection, minimizing immunosuppression, rigorous limited recipient selection, and the use of telemedicine in the outpatient setting when possible $[1 \bullet \bullet, 3,5,8,9 \bullet \bullet]$. In this paper, we explore the variations on these management strategies, to demonstrate that the 
transplant center response to the COVID-19 pandemic developed to address the individual needs of the centers, but ultimately reflected the desire to protect patients from any modifiable excessive harm.

We reviewed the published global literature for transplant centers' COVID-19 responses. The detailed findings are summarized in Table 1.

\section{Transplant Centers' Responses by Region}

\section{North America - the USA and Canada}

Our center-Montefiore Medical Center in the Bronx, New York-halted all kidney transplants starting March 22, 2020, including new evaluations of both recipients and donors. Only emergent liver, heart, and lung transplants were performed. We started doing new donor and recipient evaluations for kidney transplant via telemedicine in May 2020.With the pandemic surge winding down around June 2020 in New York City, we performed our first living donor kidney transplant in the first week of June, followed by two deceased donor kidney transplants in the same week. Currently, we are still performing both living and deceased donor kidney transplants with careful selection of recipients and donors and tailoring immunosuppression and induction to immunological risk, the psychosocial needs and living situation of the recipient, and infectious risk.

All other transplant centers in the USA discontinued living donor kidney transplants, except those on the West Coast since they were not initially as hard hit with cases as the East Coast. While some centers continued doing deceased donor transplants on a case-by-case basis, considering the level of emergency of the transplant, some centers only continued to transplant those with a lower risk of delayed graft function.

Our center initially reported a mortality rate of $28 \%$ among our kidney transplant recipients with COVID-19 [10••]. In a subsequent report, we reported an overall mortality of $20 \%$ and in-hospital mortality of $38 \%$ [11••]. Other centers in New York reported similar mortality. For immunosuppression management, the antimetabolite dose was reduced or held for most patients. Hydroxychloroquine and/or azithromycin dominated the therapeutic arsenal used. All outpatient management was switched to virtual visits via telemedicine. The handling of transplants in Canada during the pandemic mirrored that of the USA.

\section{Asia-China}

Wuhan, China, closed on January 23, 2020, due to the impending threat of COVID-19. However, the impact of COVID-19 in organ transplant recipients was minor in the Hubei Province. There were only 22 confirmed cases in organ transplant recipients (19 liver and 2 kidney) [1••]. The difference in infection rate in the transplant community compared to the rest of the community at large was credited to years of effective transplant recipient education, including practicing effective self-protection with mask compliance, hand washing, and social distancing. In response to the overwhelming healthcare demands, all organ donation stopped on January 23, 2020.

Due to the lockdown of the surrounding areas, transplant outpatient management was converted to remote follow-up. Online consultation was implemented and labs collected from home were sent to transplant centers for interpretation, including dose adjustments of calcineurin inhibitors (CNI).

COVID-19-positive transplant patients were treated by a reduction or discontinuation of immunosuppression along with supportive treatment (often with low-dose methylprednisolone) based on the severity of the lung lesions. The mortality rate was low for COVID-19-positive transplant recipients, with one death among the 22 patients. In the singlecenter study from Tongji Hospital, Zhu et al. describe pneumonia in COVID-19-positive renal transplant recipients and assess their center's treatment. They managed patients by discontinuing antimetabolites and CNIs and adding on antiviral medications [2•].

On May 25, 2020, organ transplantation resumed as the risk of COVID-19 dwindled and healthcare systems had sufficient resources.

\section{Asia-Hong Kong}

COVID-19 first emerged in Hong Kong in January 2020 after the Chinese New Year. Resource utilization shifted to treat the influx of COVID-19 cases, so the liver transplant department at Queen Mary Hospital reduced living donor liver transplant (LDLT) cases in half $[1 \bullet \bullet$. However, LDLT for urgent conditions was permitted, and the center found itself utilizing LDLT grafts for fulminant cases, who ordinarily would have received deceased donor grafts, actually doubling the LDLT rate of the prior year. There was a vast change in deceased donor liver transplantation (DDLT), with only 2 DDLT occurring in the month of February [1・•].

The center required that both potential living donors and recipients were screened for COVID-19 infection if they had symptoms or a history of recent travel. For deceased donors, screening was only performed in the presence of clinical symptoms or a recent travel history $[1 \bullet \bullet]$.

\section{Asia-Japan}

Japan's response to organ transplantation was based on the urgency of the transplant. Heart, lung, and emergent liver transplantation continued, while kidney, pancreas, and small bowel transplantation was stopped $[1 \bullet \bullet]$. 

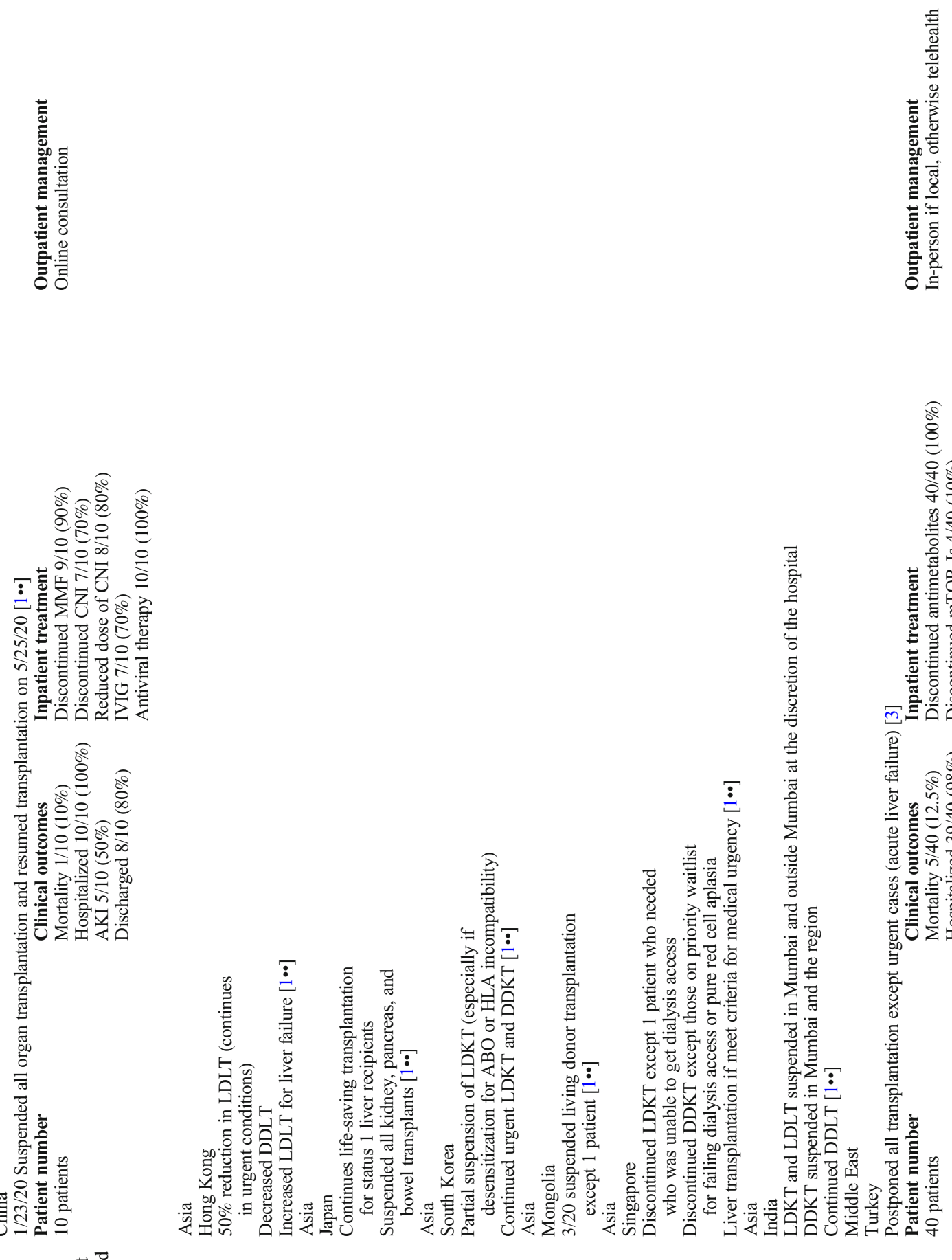

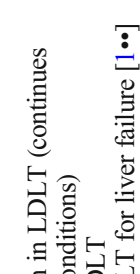

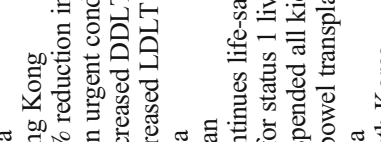

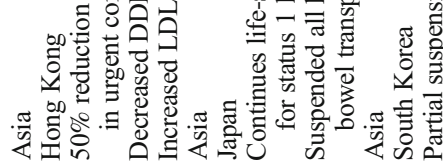

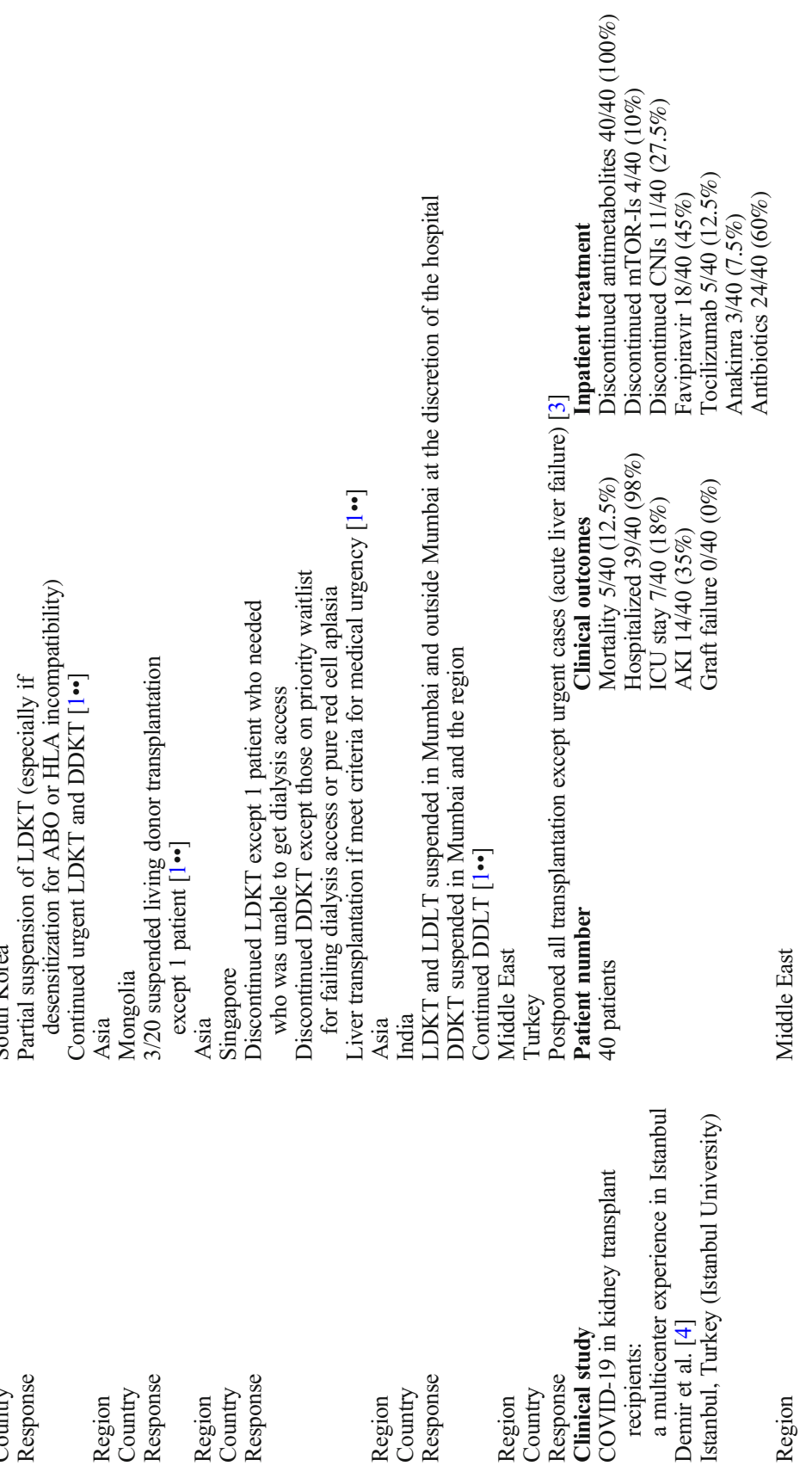




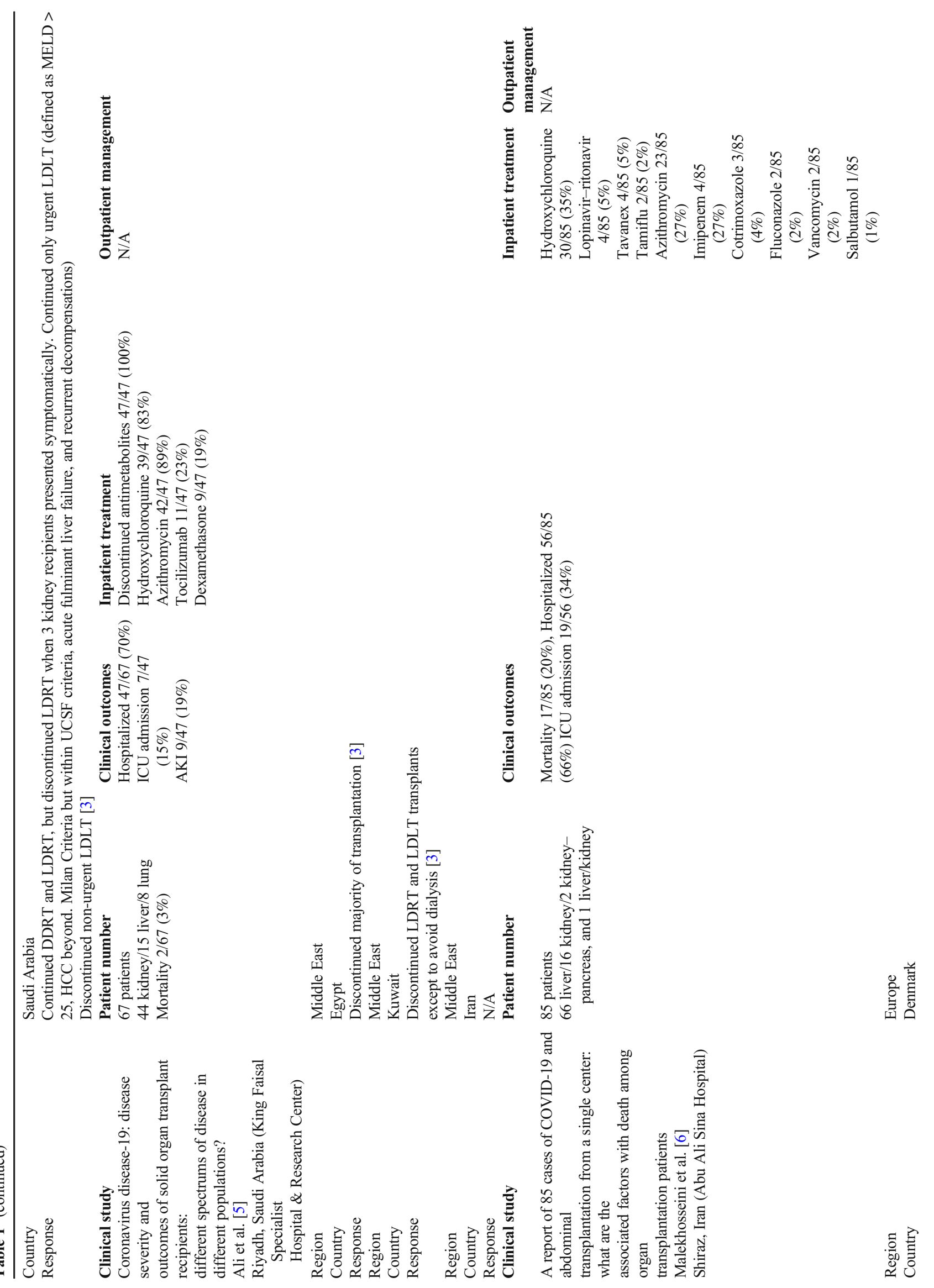


葶
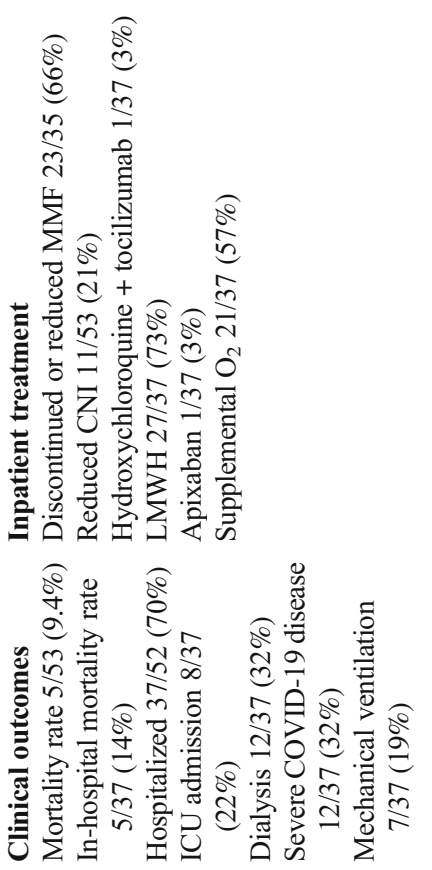
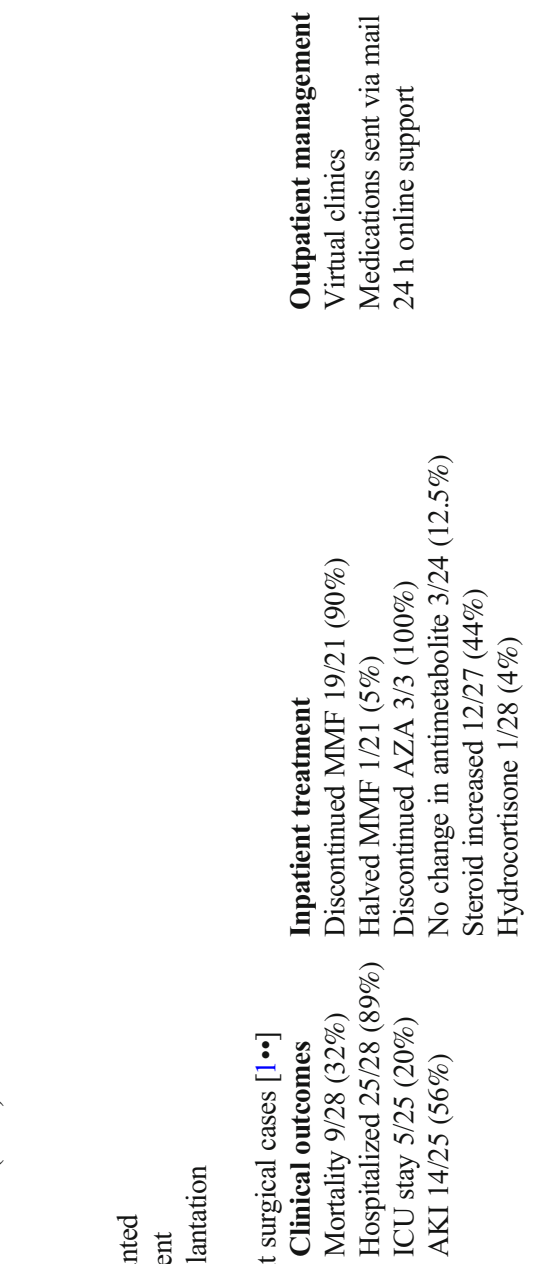
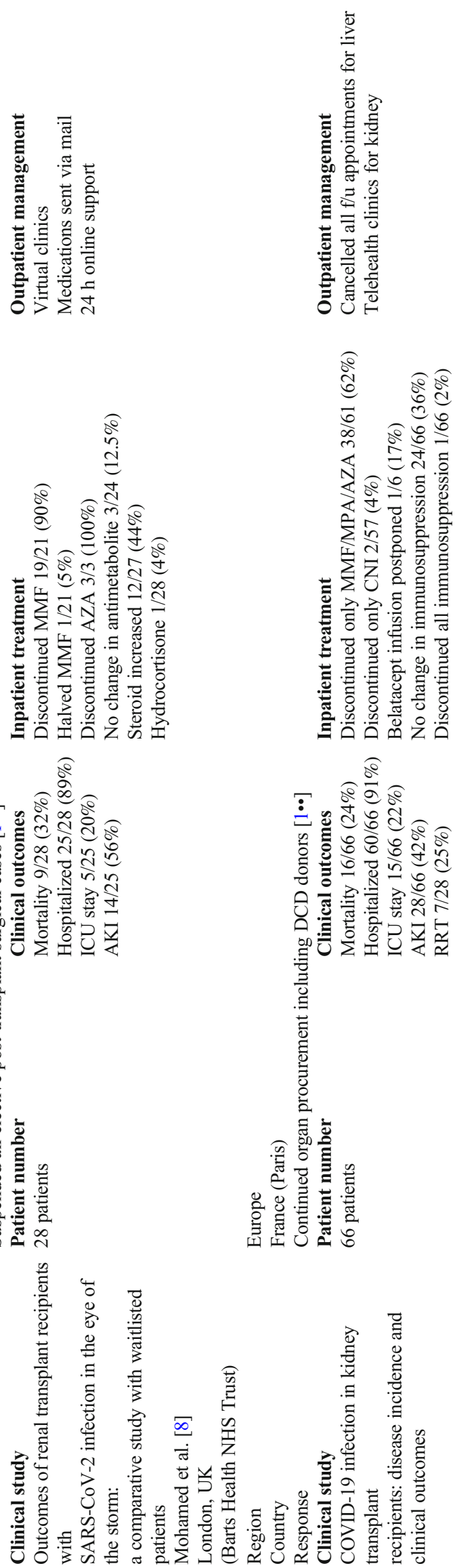

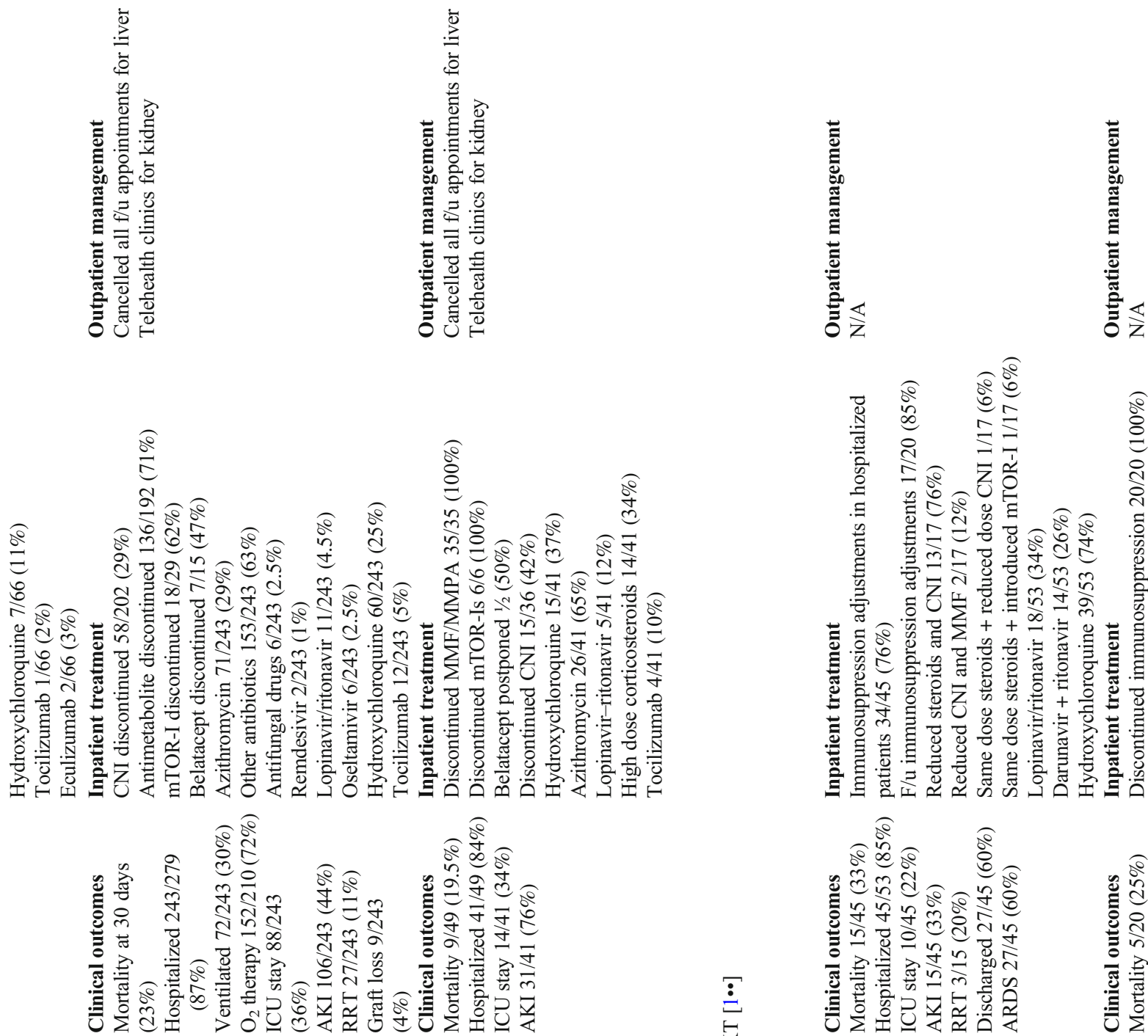

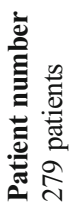
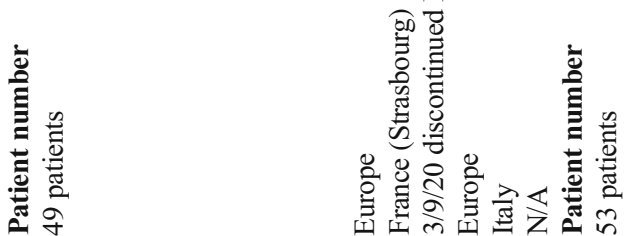

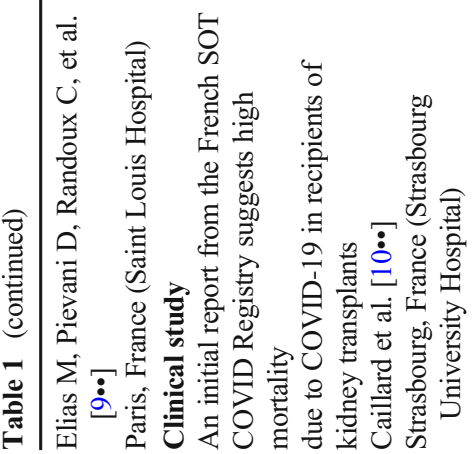
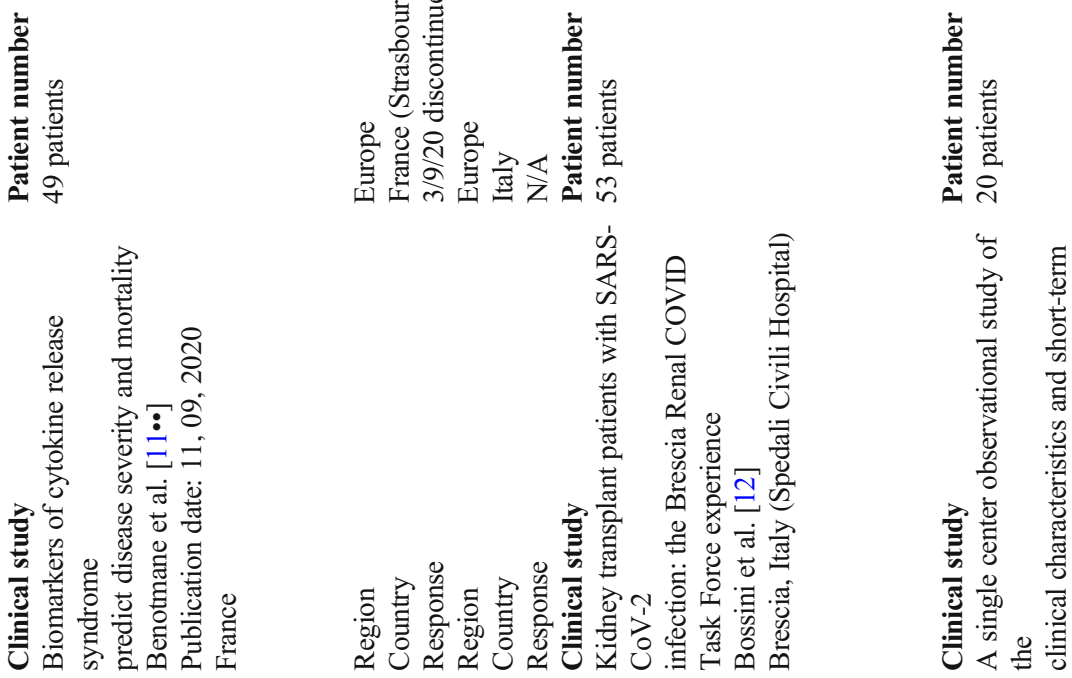


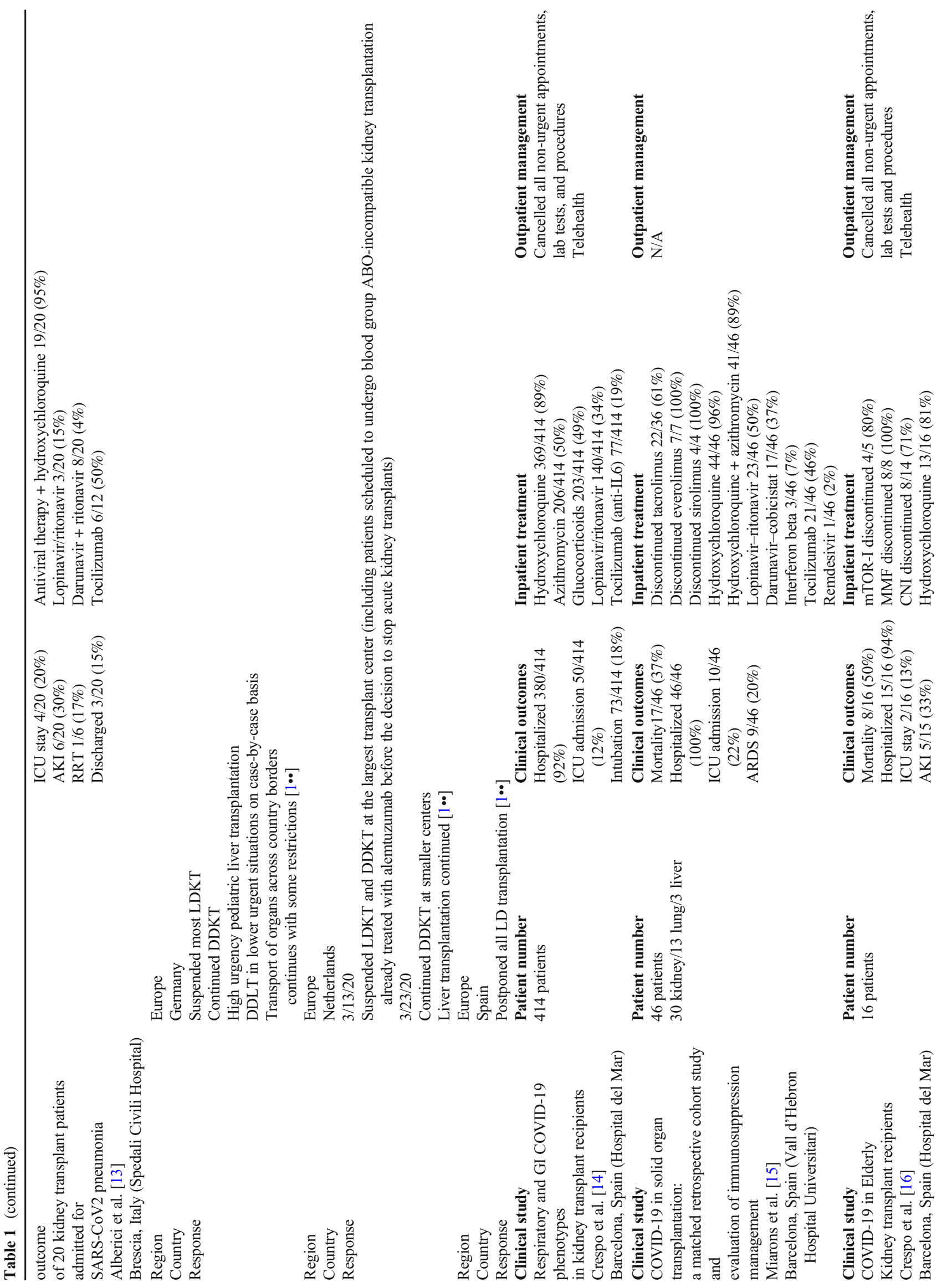




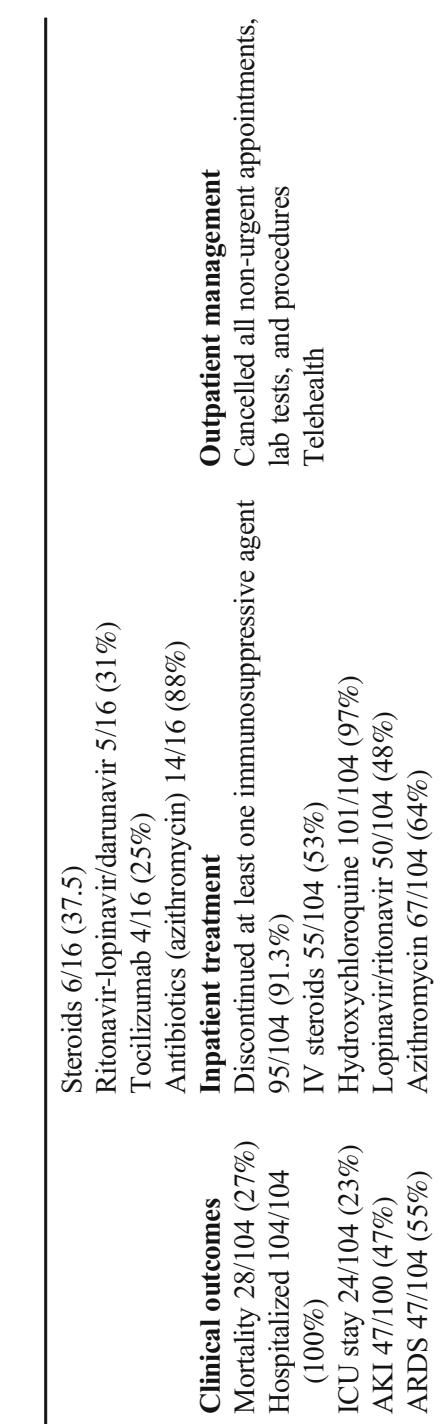

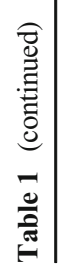

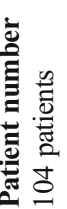

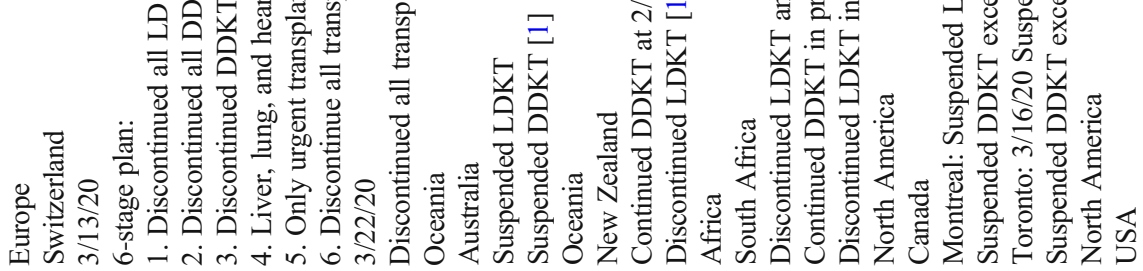

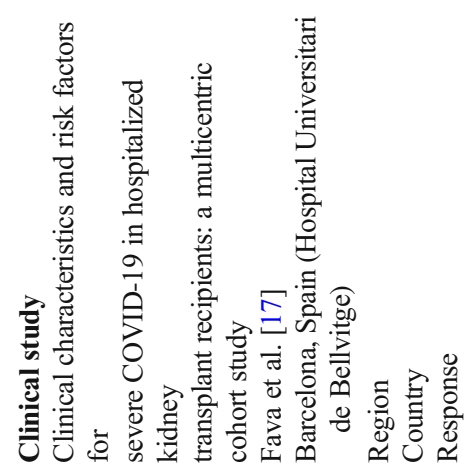

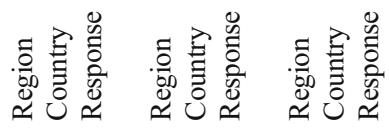

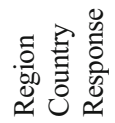

总 


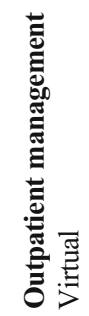

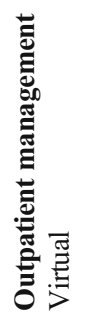

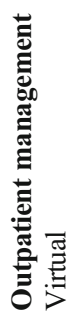

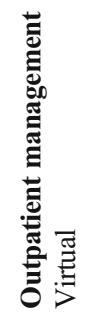

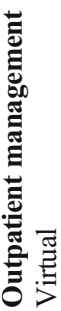

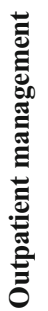
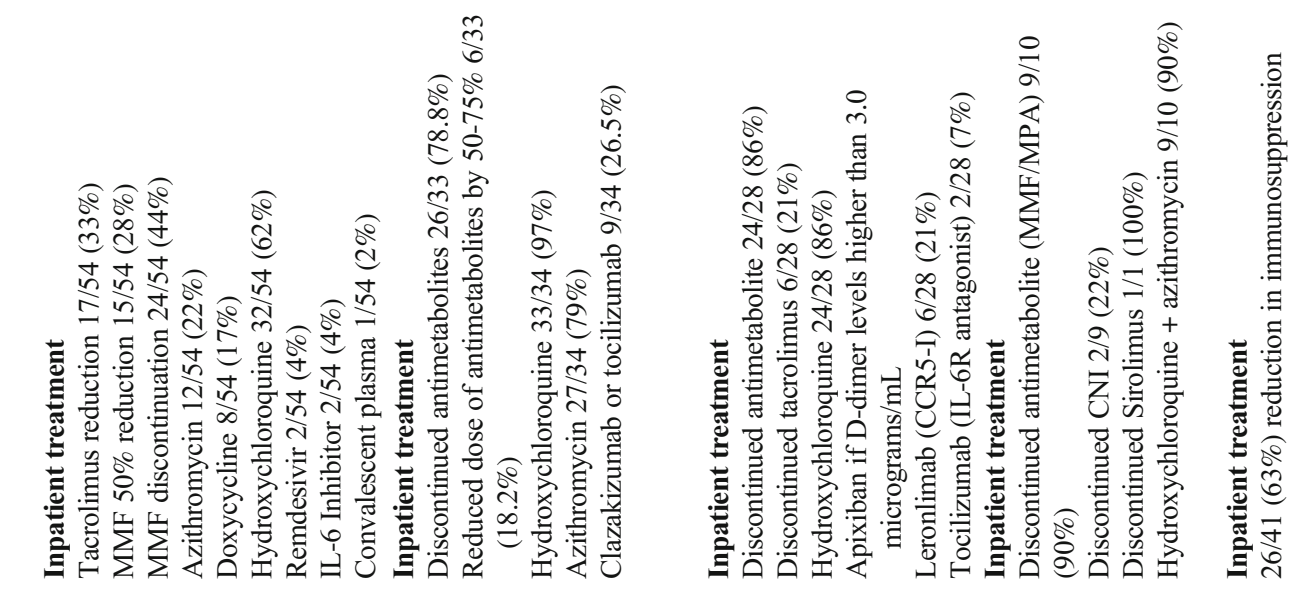

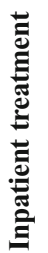
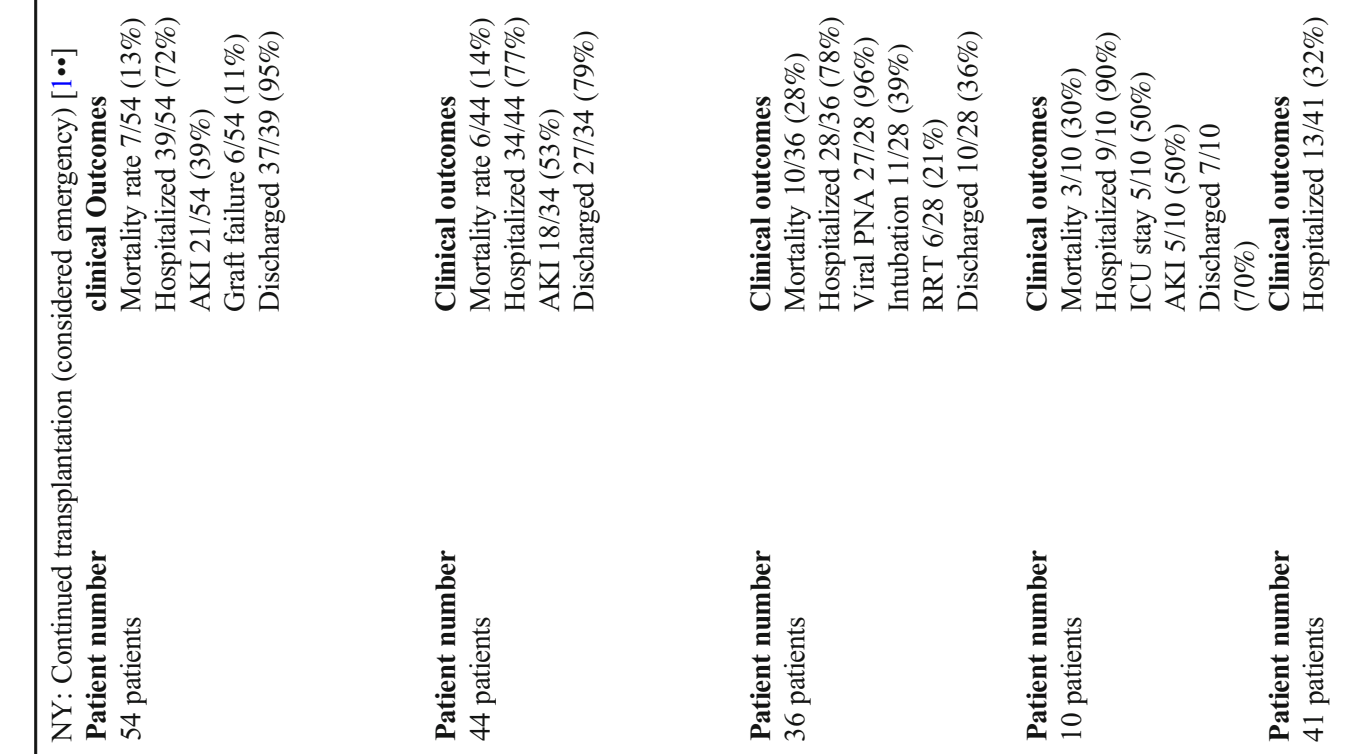

हัँّ
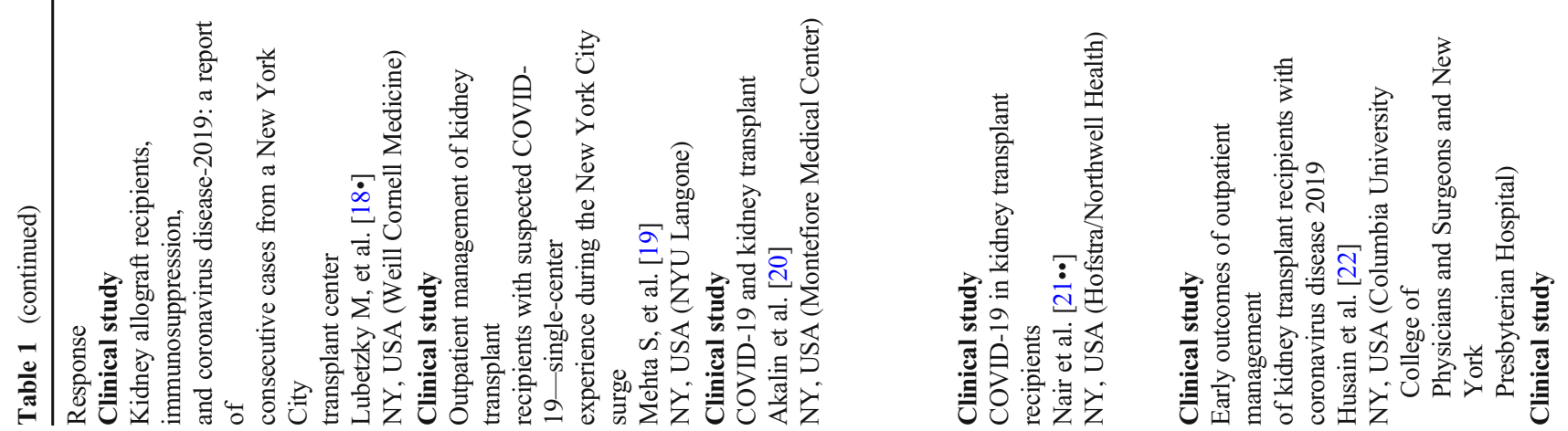


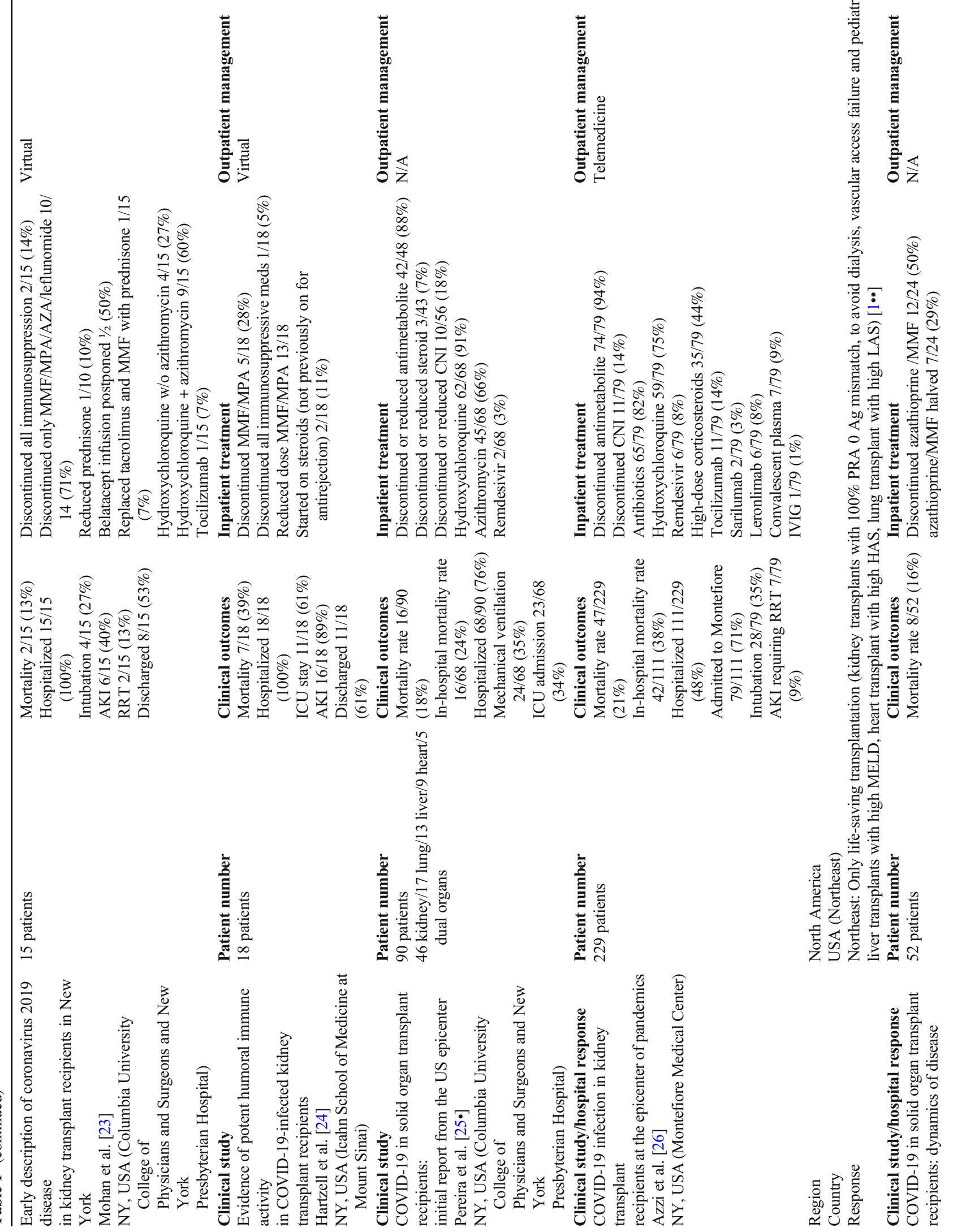




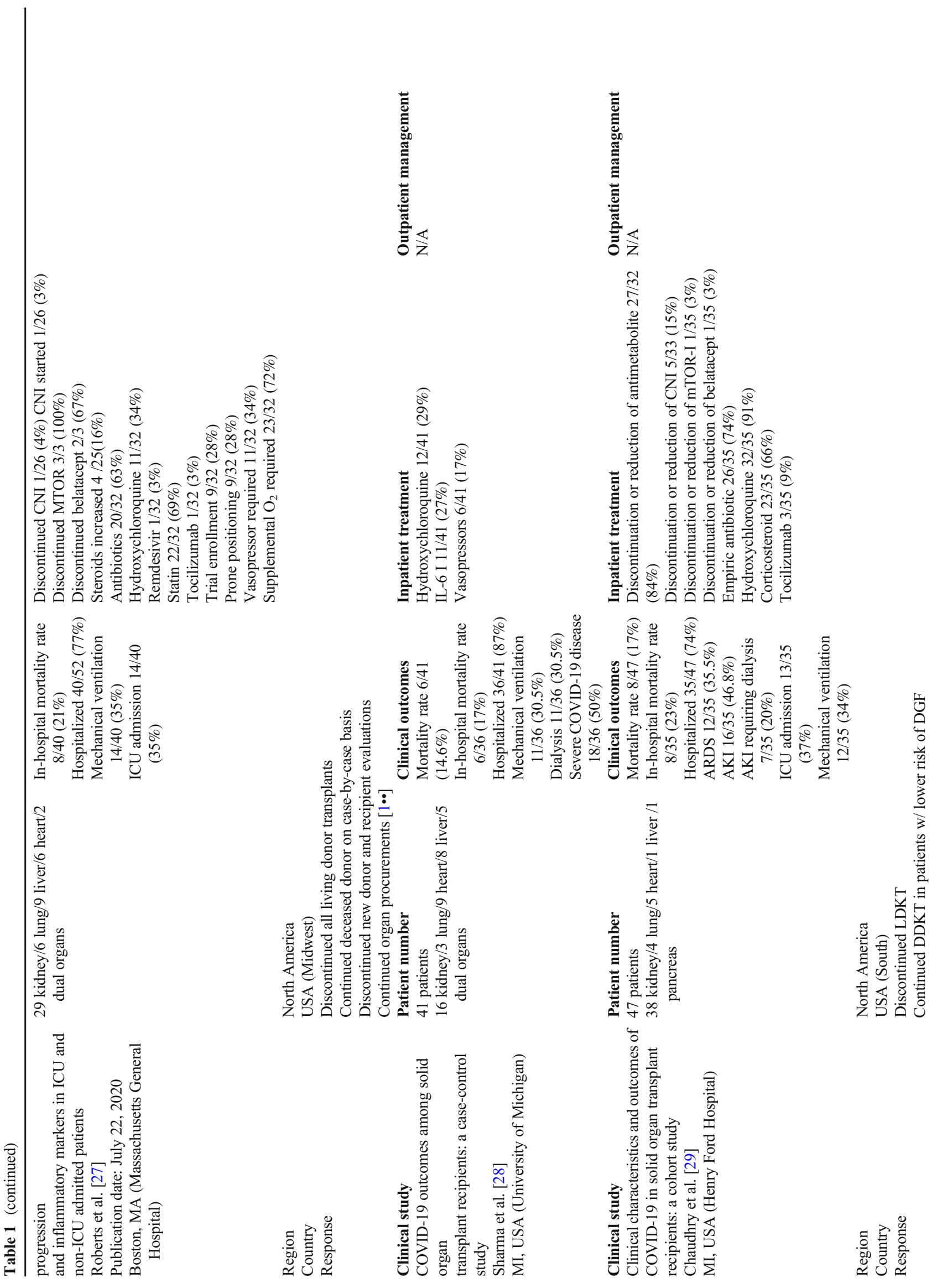



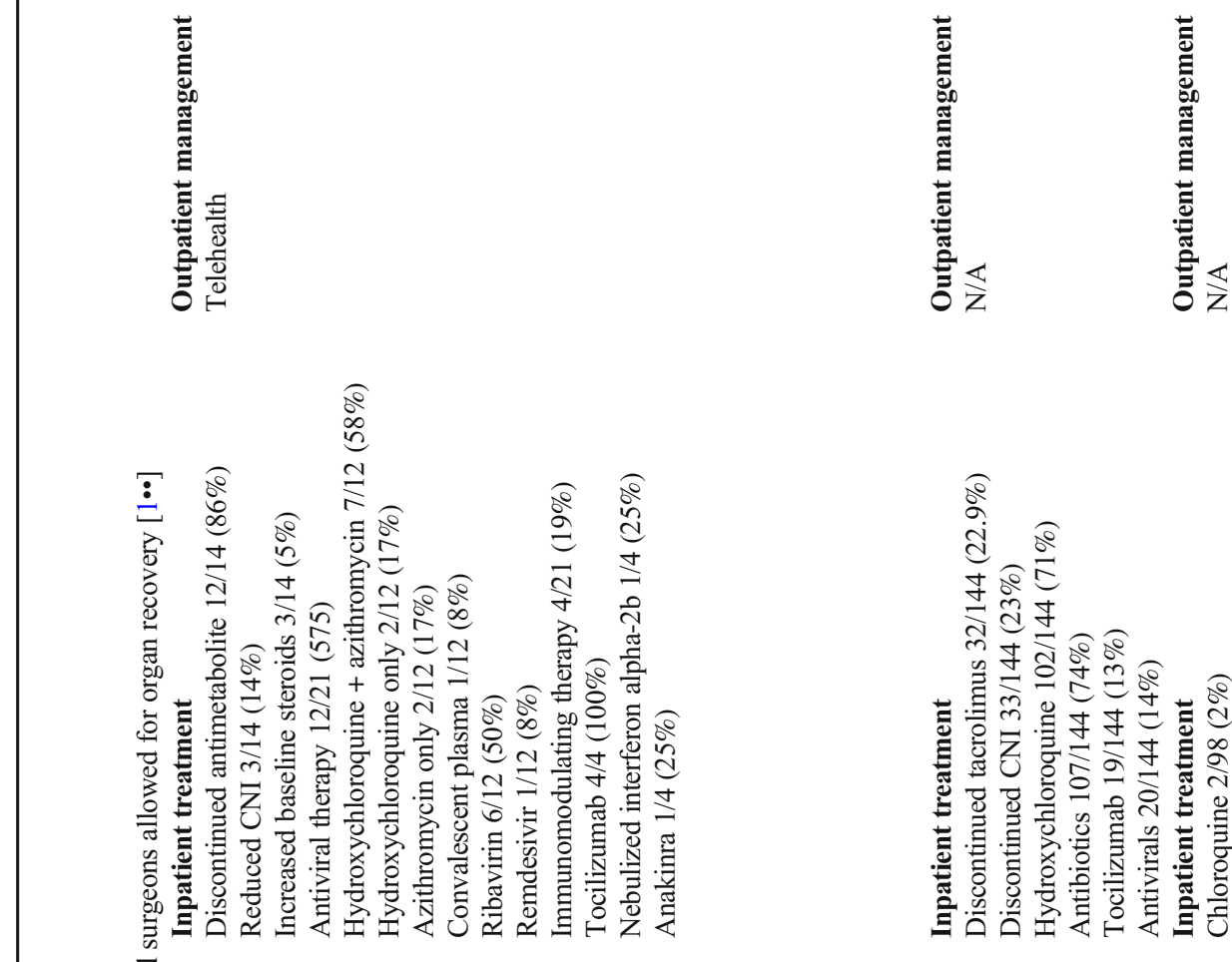

. ․ㅗㄹ

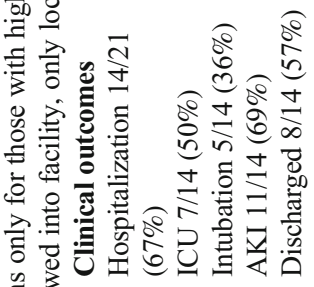

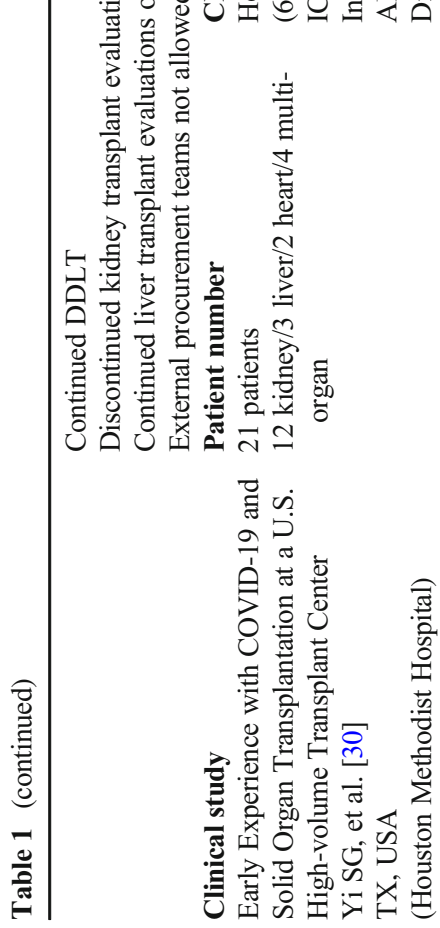

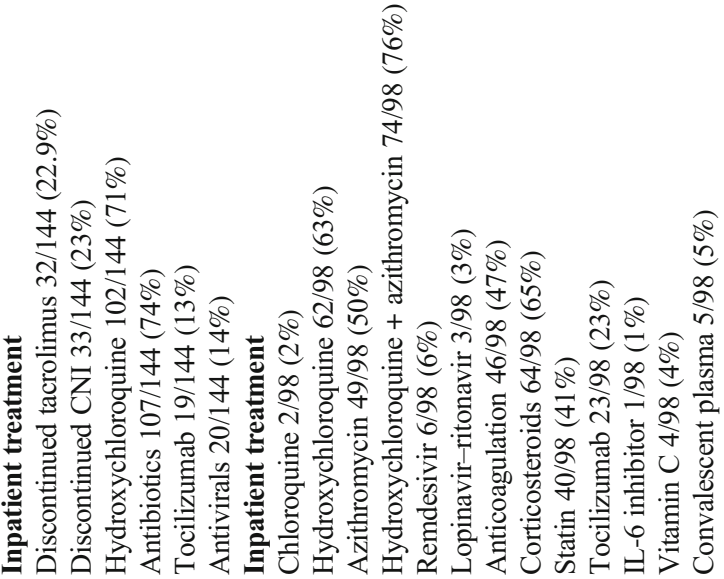

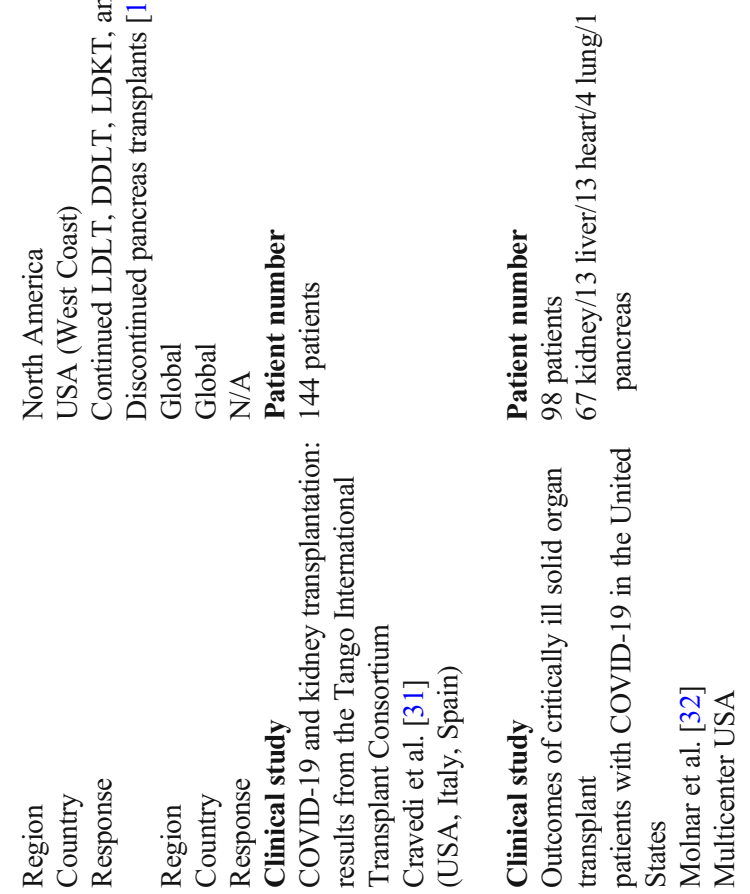


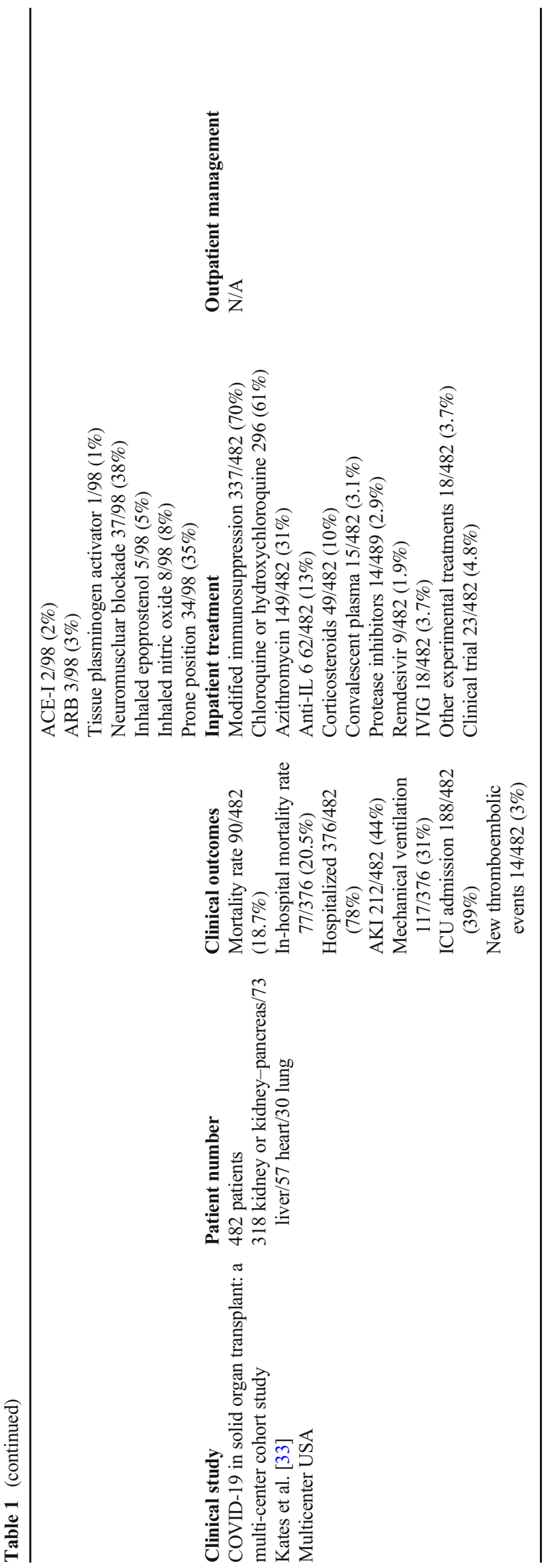

Screening for COVID-19 in donors and recipients was recommended for those with significant exposure to COVID-19, travel history to high-risk countries, or for patients with fever and respiratory symptoms. It was recommended that living donors for kidney, lung, and liver transplant stay at home or isolated in the hospital for 14 days before donation to avoid unnecessary exposure. In communities with available testing, it was recommended at 14 days and at 1 day before transplantation in both donors and recipients. Chest CT scans were also recommended before transplantation in donors and recipients $[1 \bullet \cdot]$.

Outpatient follow-up was converted to telemedicine and extended periods between visits. Additionally, to prepare patients for the lockdown, a stockpile of additional immunosuppressants was distributed to patients.

\section{Asia-South Korea}

The response to organ transplantation was mixed. Some living donor kidney transplants were postponed, especially if undergoing desensitization for $\mathrm{ABO}$ or human leukocyte antigen incompatibility, but urgent living donor kidney transplantation and deceased donor programs continued $[1 \bullet \bullet]$.

Screening for COVID-19 involved testing all deceased donors, while living donors were screened based on the center's decision. On March 13, 2020, the Korean Society for Transplantation released a guideline recommending routine COVID-19 screening of both donor and recipient $[1 \bullet \bullet]$. There was one report of a living liver donor who tested positive for COVID-19 after liver donation to her mother, but neither the donor nor the recipient developed symptoms.

\section{Asia-Singapore}

In response to the pandemic, all living kidney transplants were cancelled except for one patient who had no other access options. For this case, a nasopharyngeal swab for COVID19 was performed for both the recipient and the living donor on day 15 and day 2 before surgery [ $1 \bullet \cdot$. Additionally, chest $\mathrm{x}$-ray was performed on admission and on day 2 before surgery to assess for pneumonia. Deceased donor kidney transplantation had also been cancelled except for priority waitlisted patients with failing dialysis access or pure red cell aplasia. Liver, heart, and lung transplantations were permitted if medically urgent. One combined lung-liver was performed from a single deceased donor who underwent PCR testing for COVID-19 three times in addition to a CT thorax to exclude COVID-19 infection. These recipients were reported to be doing well.

Hospital transplant teams were divided into smaller groups working separately in different areas. They set up an acute respiratory tract infection ward where renal patients, including kidney transplant recipients, with respiratory complaints were 
admitted for COVID-19 screening, with bedside access to dialysis. Patients in the acute respiratory tract infection ward had to have two negative COVID-19 swabs before being transferred to the general ward. Due to case reports of transplant recipients presenting with gastroenteritis, transplant recipients with gastroenteritis were required to be screened by COVID-19 PCR.

Outpatient management included virtual clinics with remote monitoring and home delivery of medications.

\section{Asia-India}

In Mumbai, all living donor transplants stopped. Outside of Mumbai organ transplants continued at the discretion of each hospital. Deceased donor kidney transplants were suspended in Mumbai and the surrounding region. Neither the National Organ \& Tissue Transplant Organization nor the Regional Organ \& Tissue Transplant Organization issued edicts to stop deceased donor liver and heart transplants $[1 \bullet \bullet]$.

Outpatient follow-up was encouraged to be performed via phone and video call. If transplant patients required in-person follow-up, then they were scheduled to come into the clinic at intervals such that there would be no wait time nor contact with other patients. It was recommended that all transplant patients had a minimum of 1 month of immunosuppressants in stock $[1 \bullet \cdot$.

\section{Middle East-Turkey}

All elective procedures and surgeries were postponed across Turkey. Beginning on March 20, 2020, all private hospitals were denoted as COVID-19-only hospitals. From February 1 to April 1, 2020, in Ankara and Istanbul, only 21 liver and 23 kidney transplants were performed.

In describing a multi-center experience in Istanbul, Demir et al. found that 5 out of 40 renal transplant patients infected with COVID-19 died [12]. Inpatient management of transplant patients with COVID-19 was as follows: discontinuation of antimetabolites (both mycophenolate mofetil and azathioprine) and continuation of CNIs, except if patients required ventilation with a severe pneumonia. The interleukin-6 inhibitor, tocilizumab, was considered to treat severe cytokine release symptoms $[9 \bullet \bullet]$.

Outpatient follow-up was mostly via telemedicine.

\section{Middle East-Saudi Arabia}

The Saudi Center for Organ Transplant (SCOT) addressed the dilemmas facing the transplant community during the pandemic and issued a position statement that provided guidelines and recommendations for deceased and living donation. All deceased donors were to be screened for COVID-19 with PCR from broncheoalveolar lavage or tracheal aspirate. All positive donors were declined. COVID-19-negative donors were considered on a case-by-case basis according to the level of risk.

Only urgent liver transplants (e.g., HCC meeting UCSF criteria, acute fulminant liver failure, recurrent decompensations, MELD > 25) continued. Donor and recipients in highrisk groups were tested for COVID-19 on the day of admission. In the case of COVID-19 positivity, the transplant was cancelled. In the circumstance of a first negative COVID-19 test, a second was performed before surgery. Low-risk patients required one negative PCR test at admission. Between February 1 and April 15, 2020, 33 liver transplants including 25 from living donors were performed without COVID-19 complications.

Outpatient management involved a switch to telemedicine, blood work in the nearest laboratory with results discussed via phone, and medications delivered to the home. Only patients recently transplanted were seen in clinic. Only one post-liver transplant patient from 2016 presented positive for COVID19; no modifications were made to his medications.

Only 40 kidney transplants were performed from February 1 to April 2020; 7 of those were from deceased donors. There were no reported COVID-19 complications. Three kidney recipients presented with fever, cough, and fatigue and tested positive for COVID-19. Inpatient management consisted of azithromycin, hydroxychloroquine, and ceftriaxone and maintenance doses of low levels of tacrolimus and steroids. The living donor kidney program suspended all transplants from March until the first week of May [9••].

\section{Middle East-Egypt}

Transplant activities in Egypt were limited to live donor liver and kidney surgeries. Most governmental and university centers suspended transplant activities based on too great a risk to the donor and an unknown impact of COVID-19 on the recipient. The proposed precautions adopted for those undergoing transplant were home isolation for both the donor and recipient for 2 weeks before the transplant, to perform COVID-19 PCR twice at 48-h intervals before transplant, and to admit the recipient 3 days and donors 1 day before transplant.

Outpatient management involved telemedicine and inperson follow-up only for patients recently transplanted and those with abnormal laboratory or radiographic findings [9••].

\section{Middle East-Kuwait}

Living donor transplants were suspended on February 19, 2020, with one exception to prevent the need for dialysis. Deceased donor transplants continued, but with a rapid decline in number. From February 1 to April 1, 2020, there were no liver transplants and only 12 kidney transplants.

Screening involved testing all donors for COVID-19. 
Outpatient management focused on distributing sufficient quantity of immunosuppressants to the transplant community $[9 \bullet \bullet]$.

\section{Europe-Denmark}

National health authorities categorized transplantation as a vital surgery that should not be suspended. As a result, deceased donor kidney, liver, lung, and heart transplantations continued at all Danish centers. However, simultaneous kidney-pancreas transplantation was stopped. Organ exchange within the Scandinavian deceased donor exchange program continued. All potential deceased donors were tested for SARS-CoV-2. Already scheduled living donor transplantation was at the discretion of the transplant center (some centers cancelled and some centers continued). However, no new living donor kidney transplantations were scheduled $[1 \bullet \bullet]$.

Outpatient management was converted to telemedicine.

\section{Europe-the UK}

Patients with acute liver failure continued to be listed and transplanted. Pediatric liver transplantation continued. All LDLTs were cancelled. All procurement activity resumed as normal.

The UK government issued guidelines for transplant patients recommending 12 weeks of self-isolation due to the high risk of COVID-19 in a particularly vulnerable population. All transplant patients had 24-h online support.

In the single-center study in London at Barts Health NHS Trust, Mohamed et al. analyzed outcomes of COVID-19 infection in renal transplant recipients. Twenty-five of the 28 patients were hospitalized, with five patients requiring intensive care unit (ICU) admission. Nine patients died. Inpatient management involved discontinuation of mycophenolate mofetil and azathioprine and increased steroid doses [3].

Outpatient management involved cancelling all regular transplant assessments, with the implementation of virtual clinics. Medications were mailed to each patient's home.

\section{Europe-France}

Living and deceased donor kidney transplantation was halted. Any transplant patient suspected of having COVID-19 infection was seen in the infectious disease unit, tested by PCR, and then allocated to a COVID-19-positive hospital. Inpatient management involved discontinuation of mycophenolate mofetil and mammalian target of rapamycin (mTOR) inhibitors. In patients with acute respiratory distress syndrome, tacrolimus was discontinued as well. Each positive patient was called daily to monitor his/her progress $[1 \bullet \bullet]$.
In the single-center study at Saint Louis Hospital in Paris, Elias et al. described the clinical outcomes of COVID-19positive renal transplant recipients. Sixty of the 66 patients were hospitalized, with 15 requiring ICU care. Sixteen of the patients died. Inpatient management involved discontinuation of antimetabolites and the addition of hydroxychloroquine and monoclonal antibodies (tocilizumab and eculizumab) in a few severe cases [7].

In the multi-center study in France, Calliard et al. analyzed the outcomes of solid abdominal organ recipients with COVID-19 in a larger cohort. Of the 279 patients, 243 were hospitalized, with 88 requiring ICU care. Inpatient management was similar to the Elias et al. study cohort, with the additional use of azithromycin in 71 patients, remdesivir in 2 patients, lopinavir-ritonavir in 11 patients, antifungal drugs in 6 patients, and oseltamivir in 6 patients [13].

Outpatient care was converted to telemedicine clinics with the creation of comprehensive file of 2300 follow-up patients to reach out to about care $[1 \bullet \bullet]$.

\section{Europe_Italy}

In the multi-center study in Brescia, Italy, Bossini et al. described kidney transplant recipients infected with COVID-19. The hospitalization rate was 45 of 53 patients, with 10 requiring ICU admission. Fifteen patients died. Inpatient management consisted of adjustments to immunosuppressive medications. A reduction in steroids and CNIs occurred in the majority of patients. Antiviral medications included lopinavir-ritonavir, darunavir-ritonavir, and hydroxychloroquine [14].

In the observational study from Spedali Civili Hospital in Brescia, Italy, Alberici et al. similarly described clinical outcomes of kidney transplant recipients who tested positive for COVID-19. Out of the 20 hospitalized patients, 4 were admitted to the ICU. Inpatient management involved a discontinuation of immunosuppression in $100 \%$ of the patients and highdose steroid initiation. Antiviral medication included hydroxychloroquine, lopinavir-ritonavir, darunavir-ritonavir, and tocilizumab [15].

\section{Europe-Germany}

Throughout Germany, living kidney donor transplant surgeries were mostly suspended, while deceased donor transplantation continued. All deceased donors were screened for COVID-19; however, the test results did not change whether the organ was transplanted $[1 \bullet \bullet]$.

Outpatient management consisted of prolonging the period between visits and saving in-person visits only for those recently transplanted or with an urgent need. Tele- and videomedicine were instituted $[1 \bullet \bullet]$.

Liver transplantation followed different policies than renal transplantation. High urgency children were still eligible for 
both deceased and living transplantation. Deceased donor liver transplants were performed in lower urgency situations if the COVID-19 risk was low [1••].

Transport of organs across country borders remained active with only limited restrictions.

\section{Europe-Netherlands}

The largest kidney transplant center stopped all activity on March 13, 2020. All living donor transplants were suspended, even patients scheduled to undergo ABO-incompatible kidney transplantation who had been treated with alemtuzumab $[1 \bullet \bullet]$. The decision to stop transplantation was based on the risk of immunosuppressed patients acquiring a more severe version of COVID-19. The other six transplant centers stopped all living donor transplantation, but continued deceased donor transplantation.

Two renal transplant patients were admitted due to severe COVID-19 infection. Inpatient management consisted of not altering the maintenance immunosuppressive regimen unless life-threatening complications occurred. The liver, lung, and heart transplant programs remained active $[1 \bullet \bullet]$.

Outpatient management consisted of postponing appointments and a conversion to consultations via telemedicine or email $[1 \bullet \bullet]$.

\section{Europe-Spain}

Elective and living donor transplantation was suspended with only emergency life-saving transplants allowed to proceed $[1 \bullet \bullet]$.

In the multi-center study from Spain, Crespo et al. found that 380 of the 414 COVID-19-positive renal transplant recipients required hospitalization, with 50 requiring ICU admission. Inpatient management consisted of hydroxychloroquine, azithromycin, glucocorticoids, lopinavir-ritonavir, and a small percentage received tocilizumab [16].

In another multi-center study from Spain, Crespo et al. analyzed the effect of COVID-19 in elderly transplant recipients. Fifteen of 16 patients were hospitalized with only two patients being admitted to the ICU. The mortality rate was eight out of 16 patients, with a higher frequency in more obese and frail patients and those with underlying heart disease. Additionally, it was found that patients who died had abnormal complete blood counts and inflammatory markers that reflected more anemia, lymphopenia, higher D-dimer, C-reactive protein, and IL-6 on admission. The study concluded that COVID19 in the elderly population of kidney transplant recipients is correlated with an early and a high mortality rate. Similar inpatient management was used with discontinuation of mTOR-Is, antimetabolites, and CNIs [17].

Telemedicine was implemented to decrease the risk of COVID-19 transmission to the transplant community.
Outpatient follow-up was cancelled including all non-urgent laboratory testing and procedures $[1 \bullet \bullet]$.

\section{Europe-Switzerland}

Together, Swisstransplant and the Federal Office of Public Health coordinated a national response to the pandemic be-

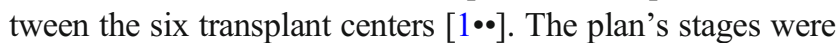
(1) stop all live donor transplantation activities; (2) stop all deceased donor pancreas and islet cell transplants; (3) stop all deceased donor kidney transplants; (4) select and tailor approach to urgent status for liver, lung, and heart transplants; (5) only urgent transplants were to be performed; and (6) stop all transplant activities $[1 \bullet \bullet]$.

On March 22, 2020, the last stage was reached and all transplant activities were stopped due to the limited hospital resources. The only exceptions were urgent cases, such as fulminant hepatitis $[1 \bullet \bullet]$.

Outpatient clinics were converted to telemedicine unless there was an urgent need for inpatient visit.

\section{Oceania-Australia and New Zealand}

Throughout Australia, transplantation was greatly reduced. Living donor and deceased donor kidney transplantation was stopped due to limited intensive care unit beds and personal protective equipment, and their being too great a risk for recipients on high-dose immunosuppression in times of a worldwide pandemic. Screening for transplantation required COVID-19 testing for all deceased donors $[1 \bullet \bullet]$.

Outpatient management transitioned to telemedicine and "apps" for consultations. Laboratory tests converted to separate labs outside of the hospital $[1 \bullet \bullet]$.

During the first wave of COVID-19 in New Zealand, deceased donor kidney transplantation continued at two of the three transplant centers. Due to the travel restrictions, living donor renal transplantation was stopped $[1 \bullet \bullet]$.

Outpatient follow-up was transformed by the use of telemedicine and remote monitoring. Only urgent patients were seen in the clinic $[1 \bullet \cdot]$.

\section{Africa-South Africa}

The healthcare system within South Africa has disproportionately distributed resources, with $85 \%$ of the population reliant on the state for medical care, but the resources are mostly situated in the private sector $[1 \bullet \bullet]$. The transplantation resources are also limited by a lack of specialty surgeons. In response to the strain on the healthcare system of South Africa, transplantation was stopped in the state sector. However, within the private sector, deceased donor transplantation continued, but was greatly limited by very few potential deceased donors $[1 \bullet \bullet]$. All living donation was halted. 


\section{Ethics}

The COVID-19 pandemic has highlighted many ethical issues in transplantation. The purpose of this section of the paper is not to give definitive statements. We have all learned that the transplant community is very vulnerable to outside forces and necessitates more resources than the ordinary patient population. The pandemic has heightened our awareness. It is not our role to decide for individual programs what is right or wrong. It is our duty to raise some of these questions, so that we begin to think and formulate strategies with potential answers when faced with this type of problem in the future.

These are some of the ethical questions that we have had to face during the pandemic; some of which may come back even sooner than we think:

1. How do we allocate scarce resources of hospital beds including ICU beds as well as staffing? Do we curtail activity in heavily affected regions?

2. Do we not perform living donor operations in regions which are heavily affected by COVID-19? Do we not expose living donors to risks in the hospital?

3. Do we transplant high-risk or low-risk recipients?

4. Do we not transplant kidney patients, but only do liver, heart, and lung as these patients have no alternative to staying alive?

5. Do we not transplant patients who cannot quarantine properly post-transplant?

6. Do we not utilize beds for potential deceased donors as resources are needed for COVID-19 patients?

7. Do we not send teams to regions where COVID-19 is rampant and do we not accept organs from these regions?

8. Do we tell patients that our program is unwilling to take the risk and that they should look to other programs that may not be as risk averse?

These are some of the questions that we as leaders in the transplant community have to consider now and potentially in the future $[18 \cdot, 19,20]$.

\section{Vaccines}

Currently, there are no proven therapeutics that work against SARS-CoV-2 virus; therefore, vaccination emerged as a crucial strategy to potentially decrease the number of infections and curtail the pandemic.

Two mRNA vaccines were given Emergency Use Authorization by the US Food and Drug Administration on December 11, 2020. Two additional ones using adenovirus as the vector for the spike protein are currently in the pipeline for approval (Table 2).
Kidney transplant recipients are known to develop low antibody response to vaccination due to the fact that they are on immunosuppression. It is unclear how they will respond to the vaccine.

mRNA vaccines have been shown to stimulate CD4 and $\mathrm{CD} 8$, cells which are reportedly decreased in patients infected with COVID-19, particularly those who are also kidney transplant recipients. Therefore, mRNA vaccines are an attractive option for kidney transplant recipients. Evaluating their response to the vaccine is to be determined in future studies $[21 \bullet \bullet, 22-24,25 \bullet]$.

\section{Global Trends in the Kidney Transplant Response}

In this review, we analyzed how different transplant centers around the world responded to the COVID-19 crisis. We noticed global trends in the varied responses to the COVID-19 pandemic. We focused on looking at transplant centers' responses to transplantation policies, the inpatient management of transplant patients infected with COVID-19, and the outpatient management of transplant recipients.

Overall, we noticed a trend of transplant centers to halt all transplantation (living and deceased donor) during peak infection times to save hospital resources and protect the vulnerable patient population. The exceptions were mostly for emergent surgery, such as kidney recipients who had exhausted all access options. It was a trend for centers to close the living donor programs first and then the deceased donor programs subsequently. However, the response to deceased donor transplants varied between countries more so than the living donor programs. In some countries, deceased donor transplants continued with modified donor and recipient criteria, while in other countries, this surgery was suspended due to the high risk of COVID-19 infection.

We noticed a few therapeutic agents dominated the inpatient management of transplant recipients infected with COVID-19. In the spring of 2020, inpatient management of kidney recipients generally consisted of hydroxychloroquine and azithromycin. The therapeutic management began to broaden in the summer and fall of 2020 to additionally include remdesivir and tocilizumab for more severe cases.

Outpatient management and follow-up was largely converted to telemedicine with remote patient monitoring. It was encouraged for transplant patients to protect themselves from COVID-19 infection and to only follow-up in person if they were a very recent transplant recipient or had an urgent or emergent indication.

The global community can learn from one another especially in times of crisis. We feel this review can share the responses of different countries and help us to understand 


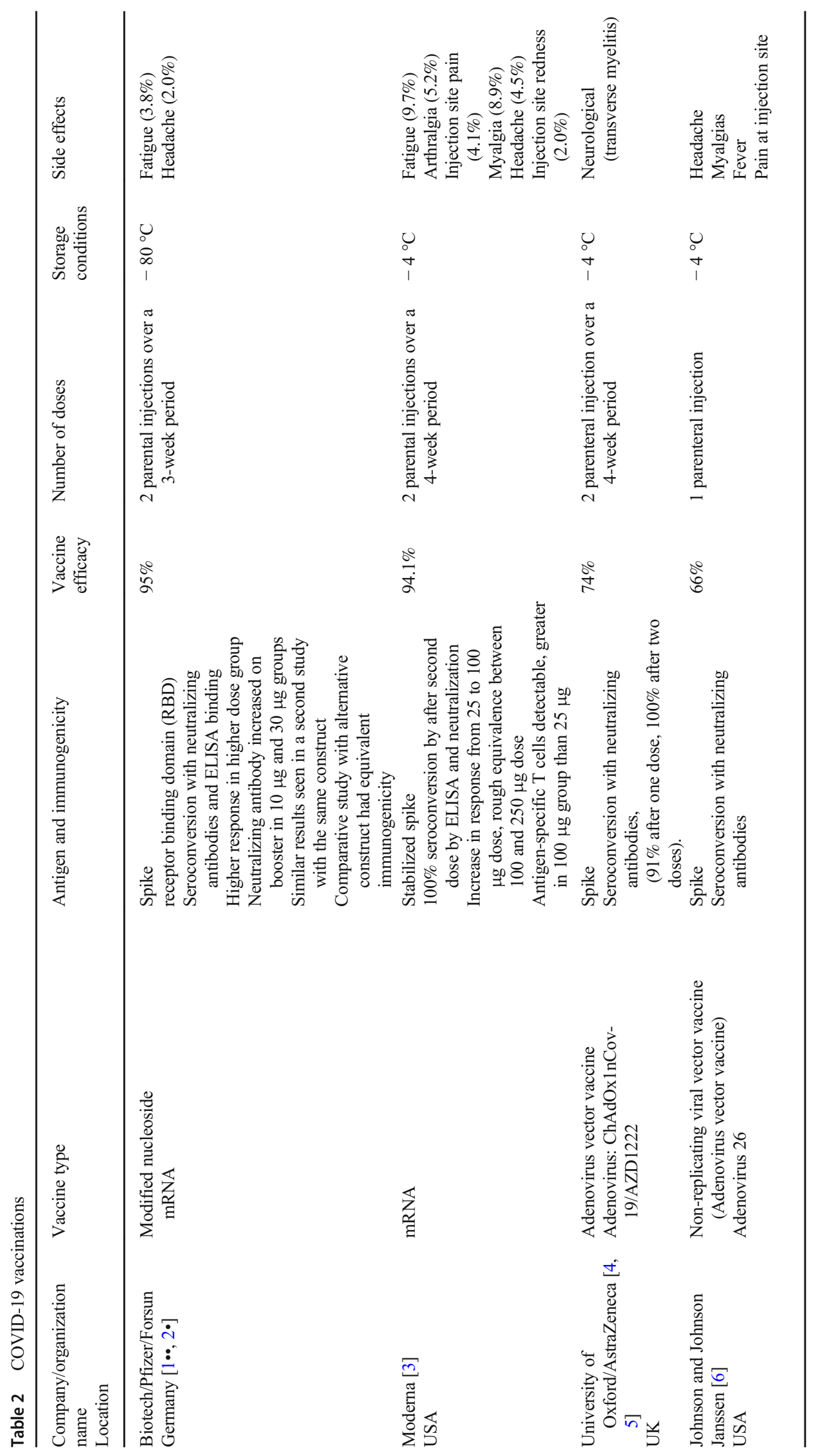


and manage the transplant population in the midst of pandemics.

\section{Conclusions}

COVID-19 is an important cause of morbidity and mortality in transplant recipients worldwide. Tailoring transplant activity during a pandemic with careful selection of donors and recipients is crucial for optimal patient outcomes. Given that there are no proven therapeutics against COVID-19, vaccination of transplant recipients is key to decreasing morbidity and mortality and eventually curtailing the pandemic.

\section{Declaration}

Conflict of Interest Yorg Azzi, Abigail Brooks, Hillary Yaffe, and Stuart Greenstein declare no conflict of interest.

Human and Animals Rights and Informed Consent This article does not contain any studies with human or animal subjects performed by any of the authors.

\section{References}

Papers of particular interest, published recently, have been highlighted as:

- Of importance

•- Of major importance

1.• Ahn C, Amer H, Anglicheau D, Ascher NL, Baan CC, Battsetset G, et al. Global transplantation COVID report March 2020. Transplantation. 2020;104(10):1974-83. https://doi.org/10.1097/ TP.0000000000003258 This reference provided a structured approach of how each country responded to COVID-19.

2. Zhu L, Gong N, Liu B, Lu X, Chen D, Chen S, et al. Coronavirus disease 2019 pneumonia in immunosuppressed renal transplant recipients: a summary of 10 confirmed cases in Wuhan, China. Eur Urol. 2020;77(6):748-54. https://doi.org/10.1016/j.eururo.2020. 03.039 This reference was one of the earliest clinical studies on kidney transplant recipients with COVID-19.

3. Mohamed IH, Chowdary PB, Shetty S, Sammartino C, Sivaprakasam R, Lindsey B, et al. Outcomes of renal transplant recipients with SARS-CoV-2 infection in the eye of the storm: a comparative study with waitlisted patients. Transplantation. 2021;105(1):115-20. https://doi.org/10.1097/TP. 0000000000003406.

4. Benotmane I, Perrin P, Vargas GG, Bassand X, Keller N, Lavaux T, et al. Biomarkers of cytokine release syndrome predict disease severity and mortality from COVID-19 in kidney transplant recipients. Transplantation. 2021;105(1):158-69. https://doi.org/10. 1097/TP.0000000000003480.

5. Yi SG, Rogers AW, Saharia A, Aoun M, Faour R, Abdelrahim M, et al. Early experience with COVID-19 and solid organ transplantation at a US high-volume transplant center. Transplantation. 2020;104(11):2208-14. https://doi.org/10.1097/TP. 0000000000003339 .
6. Cholankeril G, Podboy A, Alshuwaykh OS, Kim D, Kanwal F, Esquivel CO, et al. Early impact of COVID-19 on solid organ transplantation in the United States. Transplantation. 2020;104(11):2221-4. https://doi.org/10.1097/TP. 0000000000003391.

7. Elias M, Pievani D, Randoux C, Louis K, Denis B, Delion A, et al. COVID-19 infection in kidney transplant recipients: disease incidence and clinical outcomes. Journal of the American Society of Nephrology : JASN. 2020;31:2413-23. https://doi.org/10.1681/ ASN.2020050639.

8. Syed SM, Gardner J, Roll G, Webber A, Mehta N, Shoji J, et al. COVID-19 and abdominal transplant: a stepwise approach to practice during pandemic conditions. Transplantation. 2020;104(11): 2215-20. https://doi.org/10.1097/TP.0000000000003387.

9.• Zidan A, Alabbad S, Ali T, Nizami I, Haberal M, Tokat Y, et al. Position statement of transplant activity in the middle east in era of COVID-19 pandemic. Transplantation. 2020;104(11):2205-7. https://doi.org/10.1097/TP.0000000000003348 This reference provided an overview of the response of the Middle East transplant centers to COVID-19.

10.• Akalin E, Azzi Y, Bartash R, Seethamraju H, Parides M, Hemmige $\mathrm{V}$, et al. Covid-19 and kidney transplantation. N Engl J Med. 2020;382(25):2475-7. https://doi.org/10.1056/NEJMc2011117 This reference highlighted the significant mortality rate seen in kidney trasnplant recipients in the height of COVID-19 in NYC.

11.• Azzi Y, Parides M, Alani O, Loarte-Campos P, Bartash R, Forest S, et al. COVID-19 infection in kidney transplant recipients at the epicenter of pandemics. Kidney Int. 2020;98(6):1559-67. https:// doi.org/10.1016/j.kint.2020.10.004 This reference provided a lower mortality rate in COVID-19-positive kidney recipients which reflected a greater understanding of how to manage COVID-19 in transplant recipients.

12. Demir E, Uyar M, Parmaksiz E, Sinangil A, Yelken B, Dirim AB, et al. COVID-19 in kidney transplant recipients: a multicenter experience in Istanbul. Transplant infectious Disease : an official journal of the Transplantation Society. 2020:e13371. https://doi.org/10. 1111/tid.13371.

13. Caillard S, Anglicheau D, Matignon M, Durrbach A, Greze C, Frimat L, et al. An initial report from the French SOT COVID Registry suggests high mortality due to Covid-19 in recipients of kidney transplants. Kidney Int. 2020;98:1549-58. https://doi.org/ 10.1016/j.kint.2020.08.005.

14. Bossini N, Alberici F, Delbarba E, Valerio F, Manenti C, Possenti $\mathrm{S}$, et al. Kidney transplant patients with SARS-CoV-2 infection: the Brescia Renal COVID Task Force experience. Am J Transplant Off J Am Soc Transplant Am Soc Transplant Surg. 2020;20:3019-29. https://doi.org/10.1111/ajt.16176.

15. Alberici F, Delbarba E, Manenti C, Econimo L, Valerio F, Pola A, et al. A single center observational study of the clinical characteristics and short-term outcome of 20 kidney transplant patients admitted for SARS-CoV2 pneumonia. Kidney Int. 2020;97(6):10838. https://doi.org/10.1016/j.kint.2020.04.002.

16. Crespo M, Mazuecos A, Rodrigo E, Gavela E, Villanego F, Sanchez-Alvarez E, et al. Respiratory and gastrointestinal COVID-19 phenotypes in kidney transplant recipients. Transplantation. 2020;104(11):2225-33. https://doi.org/10.1097/ TP.0000000000003413.

17. Crespo M, Perez-Saez MJ, Redondo-Pachon D, Llinas-Mallol L, Montero MM, Villar-Garcia J, et al. COVID-19 in elderly kidney transplant recipients. Am J Transplant Off J Am Soc Transplant Am Soc Transplant Surg. 2020;20:2883-9. https://doi.org/10.1111/ajt. 16096.

18. Emanuel EJ, Persad G, Upshur R, Thome B, Parker M, Glickman A, et al. Fair Allocation of scarce medical resources in the time of COVID-19. N Engl J Med. 2020;382(21):2049-55. https://doi.org/ 
10.1056/NEJMsb2005114 This reference provided insight into the ethics behind continuing transplantation in the times of a pandemic.

19. Berger ZD, Evans NG, Phelan AL, Silverman RD. COVID-19: control measures must be equitable and inclusive. BMJ. 2020;368:m1141. https://doi.org/10.1136/bmj.m1141.

20. Potter J, Ginsberg J, Lesandrini J, Andrelchik A. To procure or not to procure: hospitals face significant ethical dilemmas regarding organ donation during the COVID-19 pandemic. The American Journal of Bioethics : AJOB. 2020;20(7):193-5. https://doi.org/ 10.1080/15265161.2020.1779861.

21.• Mulligan MJ, Lyke KE, Kitchin N, Absalon J, Gurtman A, Lockhart S, et al. Phase I/II study of COVID-19 RNA vaccine BNT162b1 in adults. Nature. 2020;586(7830):589-93. https://doi. org/10.1038/s41586-020-2639-4 This reference discussed the immunogenecity, safety, and tolerability of mRNA vaccines.

22. Walsh EE, Frenck R, Falsey AR, Kitchin N, Absalon J, Gurtman A, et al. medRxiv : the preprint server for health sciences. 2020. https:// doi.org/10.1101/2020.08.17.20176651.

23. Jackson LA, Anderson EJ, Rouphael NG, Roberts PC, Makhene M, Coler RN, et al. An mRNA vaccine against SARS-CoV-2 - preliminary report. N Engl J Med. 2020;383(20):1920-31. https://doi.org/ 10.1056/NEJMoa2022483.

24. Folegatti PM, Ewer KJ, Aley PK, Angus B, Becker S, BelijRammerstorfer $\mathrm{S}$, et al. Safety and immunogenicity of the ChAdOx1 nCoV-19 vaccine against SARS-CoV-2: a preliminary report of a phase $1 / 2$, single-blind, randomised controlled trial. Lancet. 2020;396(10249):467-78. https://doi.org/10.1016/S01406736(20)31604-4.

25. Knoll MD, Wonodi C. Oxford-AstraZeneca COVID-19 vaccine efficacy. Lancet. 2021;397(10269):72-4. https://doi.org/10.1016/ S0140-6736(20)32623-4 This reference highlighted the immunogenecity and safety of the AstraZeneca vaccine.

26. Azzi Y, Parides M, Alani O, Loarte-Campos P, Bartash R, Forest S et al. COVID-19 infection in kidney transplant recipients at the epicenter of pandemics. Kidney Int. 2020;98(6):1559-67. https:// doi.org/10.1016/j.kint.2020.10.004.

27. Roberts MB, Izzy S, Tahir Z, Al Jarrah A, Fishman JA, El Khoury J. COVID-19 in solid organ transplant recipients: Dynamics of disease progression and inflammatory markers in ICU and non-
ICU admitted patients. Transplant infectious disease : an official journal of the Transplantation Society. 2020;22(5):e13407. https:// doi.org/10.1111/tid.13407.

28. Sharma P, Chen V, Fung CM, Troost JP, Patel VN, Combs M et al. COVID-19 Outcomes Among Solid Organ Transplant Recipients: A Case-control Study. Transplantation. 2021;105(1):128-37. https://doi.org/10.1097/TP.0000000000003447.

29. Chaudhry ZS, Williams JD, Vahia A, Fadel R, Parraga Acosta T, Prashar R et al. Clinical characteristics and outcomes of COVID-19 in solid organ transplant recipients: A cohort study. American journal of transplantation : official journal of the American Society of Transplantation and the American Society of Transplant Surgeons. 2020;20(11):3051-60. https://doi.org/10.1111/ajt.16188.

30. Yi SG, Rogers AW, Saharia A, Aoun M, Faour R, Abdelrahim M et al. Early Experience With COVID-19 and Solid Organ Transplantation at a US High-volume Transplant Center. Transplantation. 2020;104(11):2208-14. https://doi.org/10.1097/ TP.0000000000003339.

31. Cravedi P, Suraj SM, Azzi Y, Haverly M, Farouk S, Perez-Saez MJ et al. COVID-19 and Kidney Transplantation: Results from the TANGO International Transplant Consortium. American journal of transplantation : official journal of the American Society of Transplantation and the American Society of Transplant Surgeons. 2020. https://doi.org/10.1111/ajt.16185.

32. Molnar MZ, Bhalla A, Azhar A, Tsujita M, Talwar M, Balaraman V et al. Outcomes of critically ill solid organ transplant patients with COVID-19 in the United States. American journal of transplantation : official journal of the American Society of Transplantation and the American Society of Transplant Surgeons. 2020;20(11): 3061-71. https://doi.org/10.1111/ajt.16280.

33. Kates OS, Haydel BM, Florman SS, Rana MM, Chaudhry ZS, Ramesh MS et al. COVID-19 in solid organ transplant: A multicenter cohort study. Clinical infectious diseases: an official publication of the Infectious Diseases Society of America. 2020. https:// doi.org/10.1093/cid/ciaa1097.

Publisher's Note Springer Nature remains neutral with regard to jurisdictional claims in published maps and institutional affiliations. 